\title{
Proton Conductive Areas on Sulfonated Poly(Arylene Ketone) Multiblock Copolymer Electrolyte Membrane Studied by Current-Sensing Atomic Force Microscopy \\ Masaya HARA, ${ }^{a}$ Takahiro MIYAHARA, ${ }^{a, b}$ Takayuki HOSHI, ${ }^{a}$ Jiwei MA, ${ }^{c}$ Masanori HARA, ${ }^{d}$ Kenji MIYATAKE, d,e Junji INUKAI,,${ }^{d} *$ Nicolas ALONSO-VANTE, ${ }^{c}$ and Masahiro WATANABE ${ }^{d, *}$
}

\author{
a Interdisciplinary Graduate School of Medicine and Engineering, University of Yamanashi, \\ 4 Takeda, Kofu, Yamanashi 400-8510, Japan \\ b Kaneka Corporation, 5-1-1 Torikai-nishi, Settu, Osaka 566-0072, Japan \\ c IC2MP-CNRS 7285 University of Poitiers, 4, rue Michel Brunet, Poitiers Cedex 86022, France \\ ' Fuel Cell Nanomaterials Center, University of Yamanashi, 6-43 Miyamae, Kofu, Yamanashi 400-0021, Japan \\ e Clean Energy Research Center, University of Yamanashi, 4 Takeda, Kofu, Yamanashi 400-8510, Japan
}

*Corresponding authors: jinukai@yamanashi.ac.jp,m-watanabe@yamanashi.ac.jp

\begin{abstract}
Proton conductive spots on the membrane surface of sulfonated poly(arylene ketone) multiblock copolymer were investigated by current-sensing atomic force microscopy (CS-AFM) under the hydrogen atmosphere with changing relative humidity, temperature, and bias voltage. The bright spots, where the hydrophilic clusters should be effectively connected inside the membrane, were distributed rather inhomogeneously on the surface at low temperature and humidity but became more homogeneous at higher temperature and humidity. The average diameter of the spots was approximately $10 \mathrm{~nm}$ at $40 \% \mathrm{RH}$, which increased to $13 \mathrm{~nm}$ at $70 \% \mathrm{RH}$. The total area of the proton conducting spots, as well as current at each spot, on the membrane surface increased at high humidity and temperature. In addition, the diameter of the proton-conductive spots and the ratio of proton-conductive area on the membrane surface continuously increased with increasing the bias voltage. This increase of the conducting area and the current should be related to the change of the bulk ionic conductivity.
\end{abstract}

(c) The Electrochemical Society of Japan, All rights reserved.

Keywords: Current-sensing Atomic Force Microscopy, Proton Exchange Membrane, Sulfonated Poly(Arylene Ketone), Proton Conductive Path

\section{Introduction}

Polymer electrolyte fuel cell (PEFC) receives a considerable attention as a promising alternative source of clean power due to its high efficiency and low emission. To achieve high performance and durability as well as reduction of the cost, the improvement of a wide range of properties for proton exchange membrane (PEM) is required, such as thermal stability, high ionic conductivity at low humidity, and elongated lifetime. ${ }^{1-3}$ Perfluorosulfonic acid (PFSA) ionomers such as Nafion ${ }^{\odot}$ are commonly used due to their high proton conductivity and chemical stability. However, low glass transition temperature, high gas permeability, environmental inadaptability as well as high production cost are issues to overcome. In recent years, membranes with sulfonated aromatic hydrocarbon (HC) structure have been extensively studied as an alternative to PFSA from the viewpoints of cost, high temperature operability, environmental friendliness, and low gas permeability, and the HCtype membranes have already demonstrated promising results. ${ }^{4-12}$ Our group has reported a series of sulfonated poly(arylene ether sulfone) (SPE) multiblock copolymers with high proton conductivity, comparable to that of Nafion, at high temperature and low humidity. ${ }^{13-18}$ Recently, we synthesized a novel HC-type membrane, sulfonated poly(arylene ketone) multiblock copolymer, or SPKbl- $1,{ }^{19}$ which has the same hydrophobic group as in SPE-bl- $1^{16,17}$ but a different hydrophilic group (Fig. 1). SPK-bl-1 showed higher proton conductivity than that of SPE-bl-1 and even higher than that of Nafion at any relative humidity.

For improving proton conductivity, it is important to understand the proton transport and distribution of proton conductive paths inside, as well as on the surface of, the electrolyte membrane. Sulfonic acid groups combined with water molecules are known to form spherically-shaped hydrophilic clusters and organize the phase-separated structure inside a Nafion membrane; the hydrophilic clusters are interconnected by narrow ionic channels to form a proton conductive network in hydrophobic fluorocarbon matrix. ${ }^{2,4,6,20}$ By using scanning transmission electron microscopy (STEM), we reported that the SPK multiblock copolymers also have a well-ordered hydrophilic/hydrophobic phase-separated structure and that the sizes of hydrophilic and hydrophobic clusters were larger than those of Nafion. ${ }^{19}$ It should be mentioned, however, that those phase-separated morphologies observed under vacuum and dry conditions are not necessarily identical with the proton conduction paths inside the electrolyte membranes, therefore, the proton conductive paths themselves must be investigated under the conditions similar to those of operating fuel cells.

Recently, atomic force microscopy (AFM) was applied for the direct observation of the proton conductive areas on membrane surfaces. $^{21-37}$ This current-sensing AFM (CS-AFM) technique has been used on Nafion ${ }^{21-32,37}$ as well as HC-based membranes. ${ }^{34-36}$ Several groups reported that the distribution of the proton conductive domains was correlated to the hydration level of the membranes. ${ }^{22,26,30-32,35-37}$ In our previous papers, each proton conductive spot on the membrane surface of SPE-bl-1 was successfully imaged by CS-AFM under the hydrogen atmosphere at various temperatures and humidities. ${ }^{36,40}$ The size of the proton conducing spots was almost unchanged regardless of the temperature and humidity, 
(a)

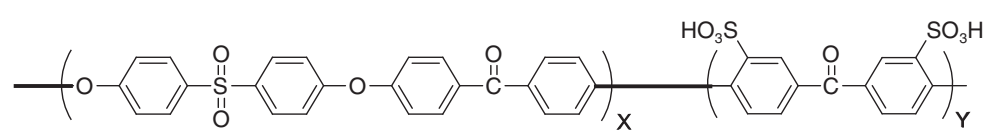

(b)

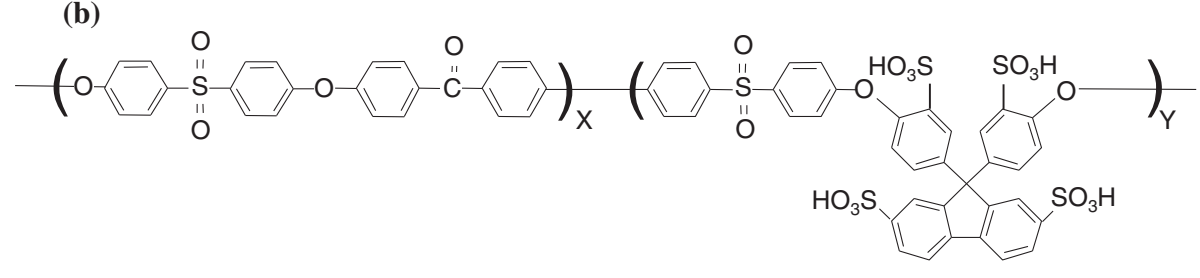

Figure 1. Chemical structures of SPK-bl-1 (a) and SPE-bl-1 (b).

whereas the number of the spots increased at higher humidity; the total area of the proton conducting spots increased accordingly on the membrane surface. ${ }^{36}$ It was further found that with increasing the bias voltage during the CS-AFM scans, the number and the diameter of proton-conductive spots on the SPE-bl-1 membrane surface continuously increased. ${ }^{40}$ In the present study, CS-AFM was applied on the surface of SPK-bl-1 membrane with changing the temperature, humidity, and bias voltage to understand its high proton conductivity.

\section{Experimental}

The molecular structure of SPK-bl-1 is shown in Fig. 1(a). The gravimetric ion exchange capacity (IEC) of the membranes was 2.33 mequiv $^{-1}$, and the numbers of repeating unit in the hydrophobic $(\mathrm{X})$ and hydrophilic $(\mathrm{Y})$ blocks were $\mathrm{X}=10$ and $\mathrm{Y}=3-5$, respectively. Membranes were formed by solution casting on a poly(ethylene terephthalate) (PET) substrate. The results of titration, water uptake, proton conductivity, as well as cell performance have been reported in our previously paper. ${ }^{19}$ For the STEM observations, the membranes were stained with lead ions by ion exchange of the sulfonic acid groups in a $0.5 \mathrm{M}$ lead acetate aqueous solution, rinsed with deionized water, and dried in a vacuum oven for $12 \mathrm{~h}$.

An SPK-bl-1 membrane was hot pressed with a gas diffusion electrode (GDE), composed of three layers, i.e., catalyst layer/ microporous layer/wet-proof carbon paper, at $140^{\circ} \mathrm{C}$ and $1.0 \mathrm{MPa}$ for $3 \mathrm{~min}$, as reported previously. ${ }^{38,39}$ The GDE was prepared by splaying (PSS, Nordson Co., Ltd.) a paste of Pt catalyst supported on carbon black (TEC10E50, 47.9 mass\%-Pt, Tanaka Kikinzoku Kogyo K.K.) containing Nafion ionomers (IEC $=0.9$ mequiv $^{-1}$, DE521, E.I. Du Pont de Nemours \& Co., Inc.) as a binder on a gas diffusion layer. A Nafion mass to carbon black ratio (dry basis) in the paste was adjusted to 0.7. The Pt loadings of electrodes were $0.5 \pm 0.1 \mathrm{mg} \mathrm{cm}^{-2}$. To improve the adhesion of SPK-bl-1 to the GDE, a thin layer of Nafion was coated on GDE. ${ }^{38}$ The SPK-bl-1 membrane on the GDE was placed on a temperature-control sample stage of the CS-AFM system.

CS-AFM measurements ${ }^{30,36}$ were carried out using a commercial AFM system (SPM-5500, Agilent) under a $5 \% \mathrm{H}_{2}$ atmosphere at the temperature of 50 and $70^{\circ} \mathrm{C}$ and the relative humidity (RH) of 40 and $70 \%$. A Pt-Ir coated silicon tip (Nanoworld) was used for the CS-AFM measurements. The morphological and current images were obtained at the contact mode with the contact force of $20 \mathrm{nN}$ on membrane surfaces previously cast and attached on a PET substrate. ${ }^{19,36,40}$ Before measurements, a $5 \% \mathrm{H}_{2} \quad\left(\mathrm{~N}_{2}\right.$ balance) gas was supplied to the environmental chamber (dead volume $=500 \mathrm{~mL}$ ) at $100 \mathrm{~mL} \mathrm{~min}^{-1}$ for $2 \mathrm{~h}$. During the AFM measurements, the flow rate was reduced to $10 \mathrm{~mL} \mathrm{~min}^{-1}$. For analyzing the current images, the threshold value was set at a background current of $3 \mathrm{pA}$.

\section{Results and Discussion}

\subsection{STEM observation of SPK-bl-1}

Phase separated structure of an SPK-bl-1 membrane was investigated by STEM. Figure 2(a) shows a cross-sectional STEM image of a lead-ion exchanged SPK-bl-1 membrane. The lead-ion exchanged sulfonic acid groups forming hydrophilic clusters are observed as dark domains. The size of the hydrophilic domains was $10 \pm 3 \mathrm{~nm}$ and the ratio of the hydrophilic domains was approximately $25 \%$. Hydrophobic regions were observed brightly with a size of $11 \pm 4 \mathrm{~nm}$. Those values were nearly the same as those of an SPE-bl-1 membrane [Fig. 1(b)]. ${ }^{36}$ The STEM image revealed that the phase separation of the SPK-bl-1 membrane was very uniform and developed due to a high concentration of sulfonic acid groups in the hydrophilic blocks. The surface of the membrane was then examined by CS-AFM.

\subsection{Water uptake and proton conductivity}

Figures 2(b) and 2(c) show the results for the water uptake and the proton conductivity, respectively, of SPK-bl- 1 at $80^{\circ} \mathrm{C}$ as a function of humidity. The water uptake of SPK-bl-1 (2.33 mequiv $\left.\mathrm{g}^{-1}\right)$ was nearly twice as large as that of SPE-bl-1 (1.70 mequiv $\left.\mathrm{g}^{-1}\right)^{16}$ and almost three times that of Nafion at any humidity. ${ }^{19}$ The proton conductivity of SPK-bl-1 increased steadily with humidity. With the increase of humidity from 40 to $70 \%$ $\mathrm{RH}$, the water uptake increased by 1.6 times, accompanied by a noticeable increase of the proton conductivity by $6-7$ times. The proton conductivity of SPK-bl-1 was higher nearly by a factor of 2 than that of SPE-bl-1 $1^{16,17}$ at any humidity and higher than that of Nafion, especially at a high humidity. ${ }^{19}$ The high IEC of SPK-bl-1 can be contributing to this high proton conductivity.

\subsection{CS-AFM imaging of SPK-bl-1 membrane under various temperatures and humidities}

The CS-AFM measurements on the SPK-bl-1 membrane were carried out under $5 \% \mathrm{H}_{2}$. Figure 3 shows typical topographic images of the membrane surface in an area of $1 \mu \mathrm{m} \times 1 \mu \mathrm{m}$ at temperatures of 50 and $70^{\circ} \mathrm{C}$ and humidities of 40 and $70 \%$ RH. The corrugations were only around 2 to $5 \mathrm{~nm}$. On the surface observed at $40 \% \mathrm{RH}$, lines with a width of tens of nanometers are seen, which might be reflecting the shape of the PET surface. At $70 \% \mathrm{RH}$, the corrugation of the membrane surface was slightly increased possibly because of swelling of the membrane, and the narrow lines observed at $40 \%$ RH became less prominent. Figure 4 shows the current images simultaneously obtained. Tip bias voltage was kept at $-0.6 \mathrm{~V}$ during the CS-AFM measurement. The bright areas represent conductive and the dark areas non- or low-conductive regions. The correlation between morphological images and current images was not observable (Figs. 3 and 4). A closer look at the CS-AFM images in Fig. 4 reveals an ellipse shape of the proton conducting spots in the 
(a)

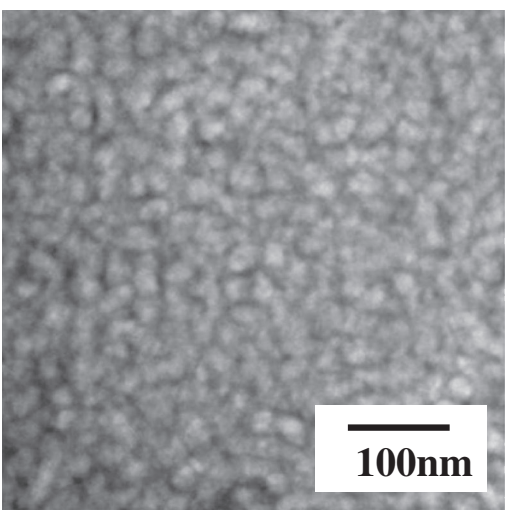

(b)

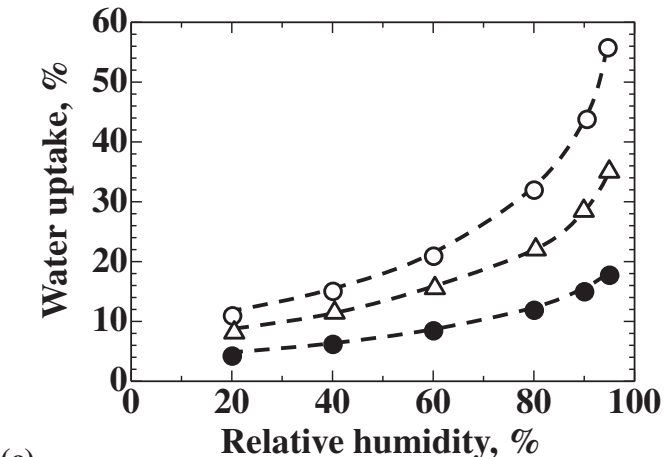

(c)

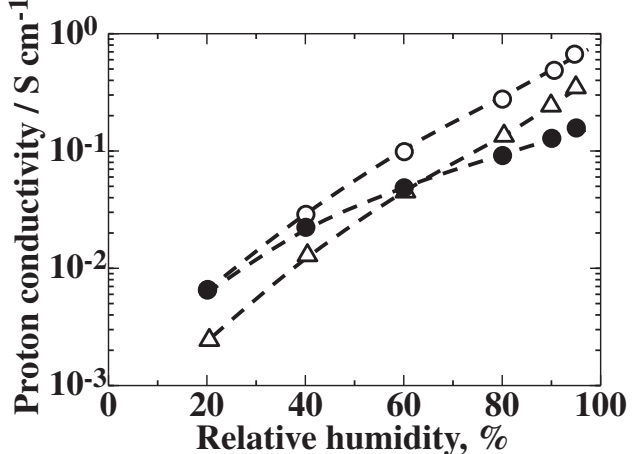

Figure 2. STEM image (a) of an SPK-bl-1 membrane in vacuum at room temperature. Water uptake (b) and proton conductivity (c) of SPK-bl-1 (open circle), SPE-bl-1 (open triangle) and Nafion (filled circle) at $80^{\circ} \mathrm{C}$.

horizontal scanning direction, probably due to the contact between the surface and the AFM tip. Therefore, the actual diameter was taken as the size of the spot perpendicular to the scanning direction. ${ }^{36,40}$ The proton conductive spots were about ten nanometers in diameter and distributed rather inhomogenously on the surface especially at low temperature and humidity. The number of the spots increased and the spots became brighter at higher temperature and humidity, and the distribution became much more homogeneous. The influence of humidity increase from 40 to $70 \%$ $\mathrm{RH}$ was larger than that of temperature rise from 50 to $70^{\circ} \mathrm{C}$.

Figure 5 shows the histograms of the proton conducting spots observed by CS-AFM under different conditions. The temperature gave little influence on the size and its distributions, whereas the humidity gave a large influence. At $40 \% \mathrm{RH}$, the size distribution was unimodal, and the average diameter of the proton conducting spots was approximately $10 \mathrm{~nm}$. At $70 \% \mathrm{RH}$, two regions existed for the size distribution: one from 6 to $16 \mathrm{~nm}$, the other from 20 to $28 \mathrm{~nm}$. In the smaller spot region, the average diameter of the spot became larger to $13 \mathrm{~nm}$ at $70 \% \mathrm{RH}$ from $10 \mathrm{~nm}$ at $40 \% \mathrm{RH}$. The size of the proton conductive spots on the membrane surface at $40 \% \mathrm{RH}$

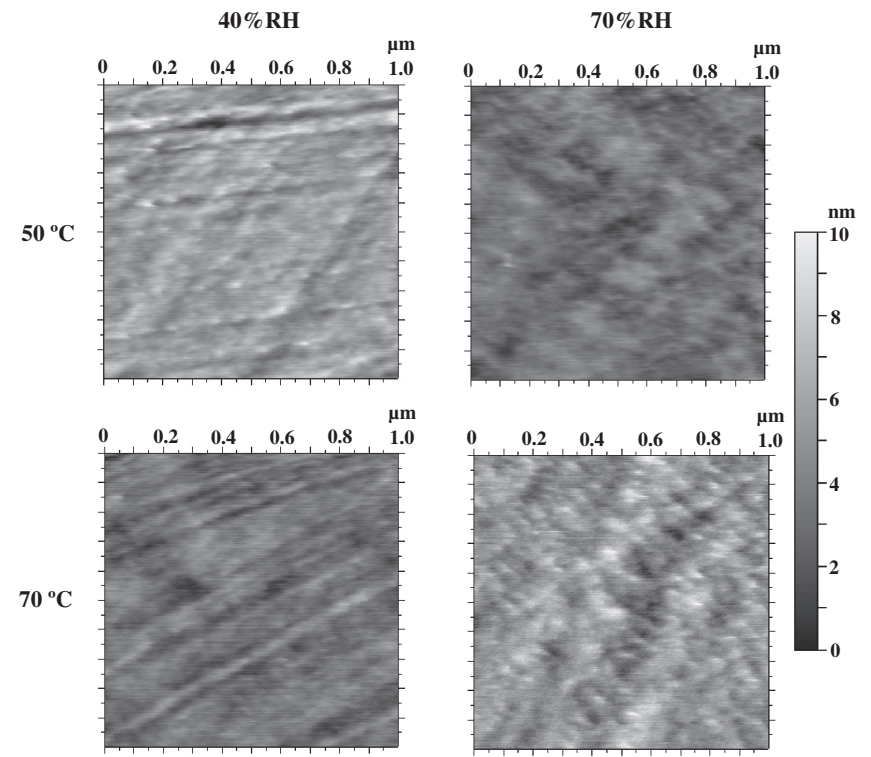

Figure 3. Morphology on an SPK-bl-1 membrane surface under $5 \% \mathrm{H}_{2}$ at $50 / 70^{\circ} \mathrm{C}$ and $40 / 70 \% \mathrm{RH}$. Tip bias voltage $=-0.6 \mathrm{~V}$.

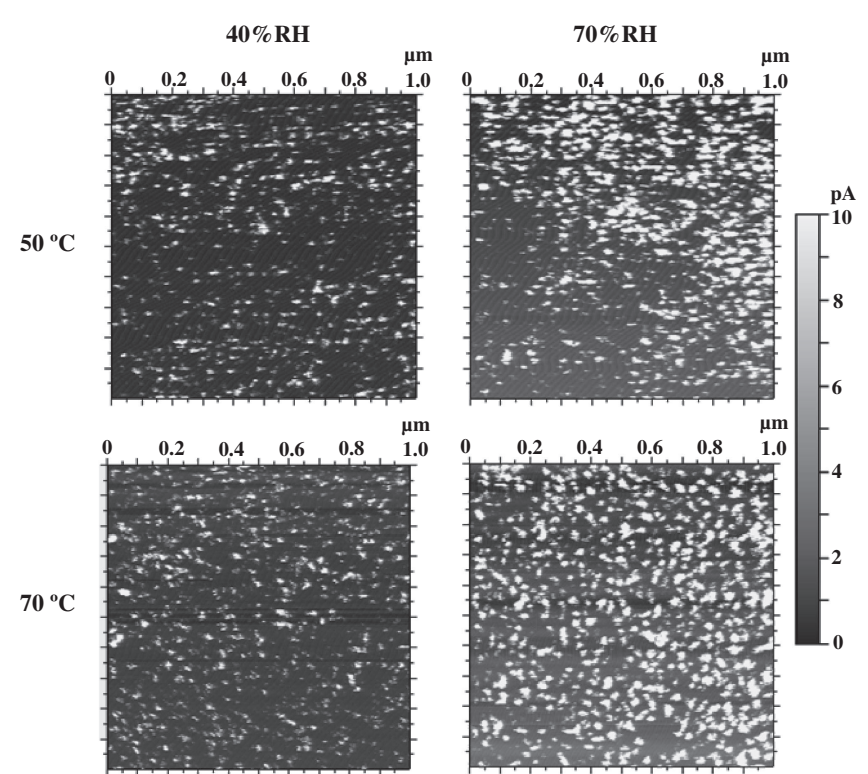

Figure 4. Current images of the SPK-bl-1 membrane under $5 \% \mathrm{H}_{2}$ at $50 / 70^{\circ} \mathrm{C}$ and $40 / 70 \% \mathrm{RH}$. Tip bias voltage $=-0.6 \mathrm{~V}$. Topography images (Fig. 3) and current images were simultaneously obtained. (a)

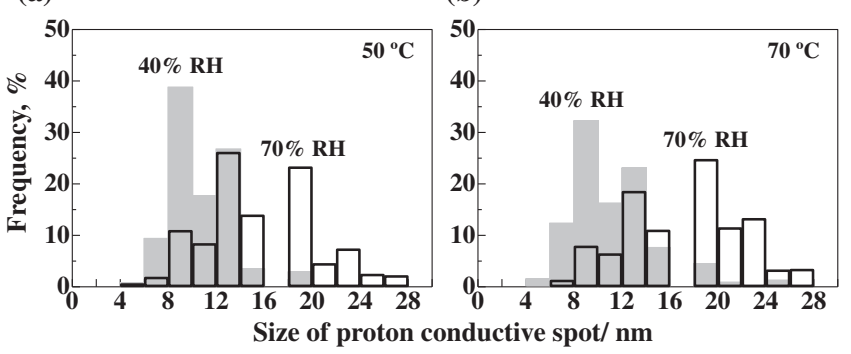

Figure 5. Size distributions of the proton conductive spots on SPK-bl-1 under $5 \% \mathrm{H}_{2}$ at $50^{\circ} \mathrm{C}$ (a) and $70^{\circ} \mathrm{C}$ (b). Results at 40 and $70 \% \mathrm{RH}$ are shown by gray and white bars, respectively. 
(a)

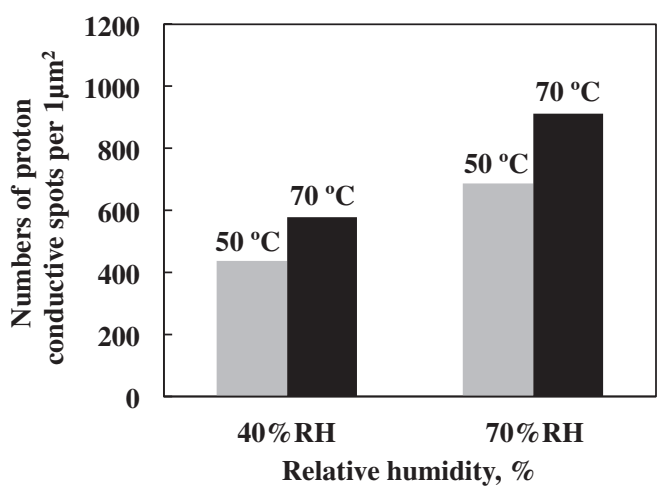

(b)

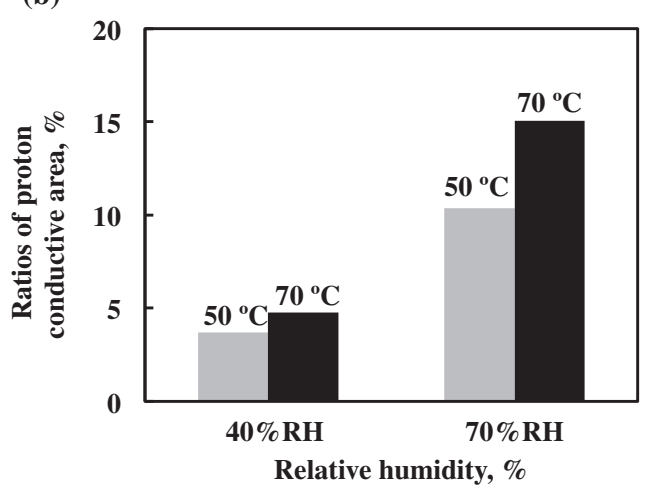

Figure 6. Numbers in $1 \mu \mathrm{m}^{2}$ (a) and the area ratios (b) of the proton conducting spots at different temperatures and humidities.

was comparable to that of the hydrophilic clusters observed in the STEM image [Fig. 2(a)]. The enlargement of the spot size is different from the results obtained on SPE-bl-1, where the diameter remained unchanged at different temperatures and humidities. ${ }^{36}$ This enlargement of the conductive spots might be attributed to the higher water uptake of SPK-bl-1 than SPE-bl-1. In the larger spot region from 20 to $28 \mathrm{~nm}$, the diameter has stepped to twice the size of the hydrophilic domains observed at $40 \% \mathrm{RH}$. Therefore, the appearance of the latter region could be explained by the merging of two (or three) adjacent spots detected as a single spot at the apex of a tip of CS-AFM. The merging of the spots was also observed on an SPE-bl-1 membrane at a high voltage. ${ }^{40}$

Figures 6(a) and 6(b) show the total numbers of the proton conducting spots and the surface allotment ratio of the conducting area, respectively, in the scanning area of $1 \mu \mathrm{m}^{2}$, obtained from the CS-AFM images in Fig. 4. The number of the spots increased significantly at higher humidity as well as higher temperature, e.g., from 410 to 620 at $50^{\circ} \mathrm{C}$ and from 590 to 920 at $70^{\circ} \mathrm{C}$ with the humidity change from 40 to $70 \% \mathrm{RH}$. The increase in the number of the proton conducting spots at a higher humidity should be due to the better-connected proton transport network inside and/or at the surface of the membrane. The same statistical analysis has been performed on SPE-bl- $1,{ }^{36}$ in which the number of the spots on SPEbl-1 increased from 180 to 320 at $50^{\circ} \mathrm{C}$ and from 90 to 540 at $70^{\circ} \mathrm{C}$ with the humidity change from 40 to $70 \% \mathrm{RH}$. Therefore, the number of conducting spots on SPK-bl-1was more than two times larger than that on SPE-bl-1. This efficient proton network could be a reason for the high proton conductivity on SPK-bl-1.

The total area of the proton conducting spots at higher humidity and higher temperature was larger than that at a low humidity and low temperature as shown in Fig. 6(b). By CS-AFM, the percentage of the total proton conductive regions on the surface was calculated as $4-15 \%$, smaller than the ratio of hydrophilic phase measured by (a)

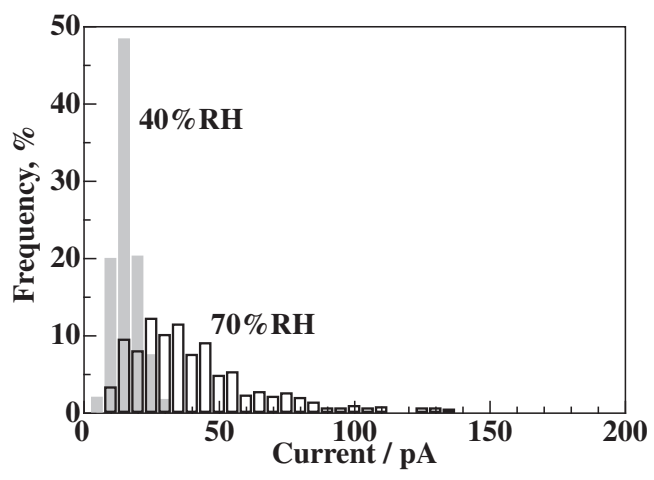

(b)

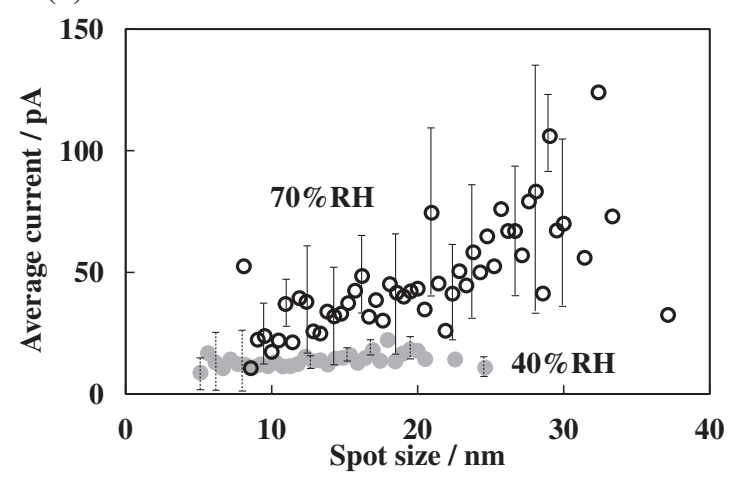

Figure 7. (a) Distributions of current at the center of each proton conducting spot. (b) Relationship between the spot size and the current at the center of the spot with standard deviations. Temperature $=50^{\circ} \mathrm{C}$. Humidity $=40$ and $70 \%$ RH. Tip bias voltage $=$ $-0.6 \mathrm{~V}$.

STEM, 25\%. Therefore, the conductive paths might still be improved. The ratio of the conductive area observed on SPE-bl-1 was much smaller, less than $6 \%$ even at $70^{\circ} \mathrm{C}$ and $70 \% \mathrm{RH}$, compared with $15 \%$ on SPK-bl- $1 .{ }^{36}$ Therefore, the phase separated structure and the higher water uptake of SPK-bl-1 with densely sulfonated hydrophilic groups must have improved the connectivity of the hydrophilic clusters, resulting in the high proton conductivity.

It is difficult to evaluate the proton flux at each conductive spot, because the tip contact area (presumably several $\mathrm{nm}^{2}$ ) is smaller than the spot area (larger than $100 \mathrm{~nm}^{2}$ ). In order to represent the proton flux at each spot, we chose the maximum current at the middle of the spot. Figure 7(a) shows the histograms of current at the center of each proton conducting spot at 40 and $70 \% \mathrm{RH}$ at a temperature of $50^{\circ} \mathrm{C}$. The average current obtained at $40 \% \mathrm{RH}$ was $16 \pm 10 \mathrm{pA}$. With increasing humidity, the current increased and its distribution much broadened. The current distribution obtained at $70 \% \mathrm{RH}$ became $40 \pm 30 \mathrm{pA}$, therefore, not only the size and the number of proton conducting spots but also the flux of protons through a proton conducting path increased at higher humidity in the membrane with hydrophilic clusters hydrated sufficiently and connected efficiently. Additionally, the relationship between the spot size and the current at the center of the spot was investigated [Fig. 7(b)]. At $40 \%$ RH, the current detected was nearly constant, $16 \mathrm{pA}$, independent of the spot size. At $70 \% \mathrm{RH}$, the current apparently increased as the spot size became larger. Noticeably, the standard deviations of the current became very large especially at large spots. The large deviations of current at a higher humidity might indicate that, in spite of the larger hydration, the connectivity of hydrophilic clusters were different at different paths. Detailed analysis of the path structure at a molecular level should be required to understand the differences among the proton conductive spots. 

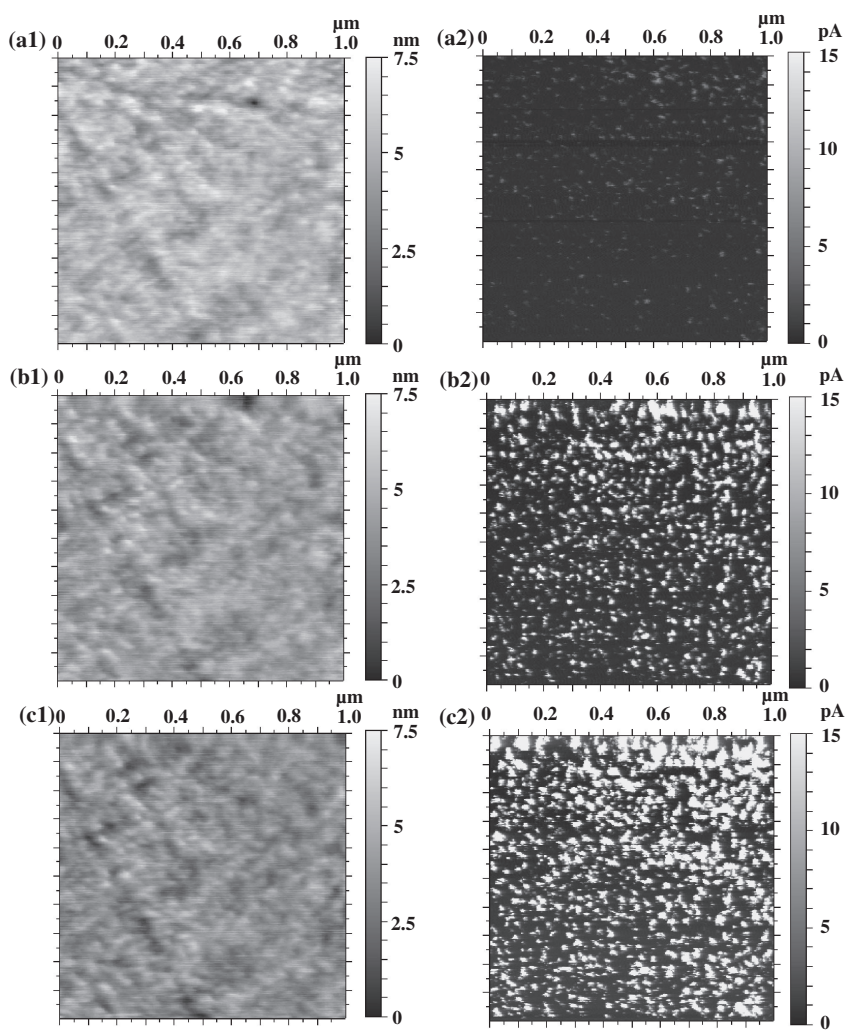

Figure 8. Topography $(\mathrm{a} 1, \mathrm{~b} 1, \mathrm{c} 1)$ and current $(\mathrm{a} 2, \mathrm{~b} 2, \mathrm{c} 2)$ images on SPK-bl-1 obtained at -0.4 (a1, a2), -0.6 (b1, b2), and $-0.8 \mathrm{~V}$ $(\mathrm{c} 1, \mathrm{c} 2)$ at $50^{\circ} \mathrm{C}$ and $40 \% \mathrm{RH}$.

\subsection{CS-AFM imaging of SPK-bl-1 under different bias voltages}

In our previous paper, the effects of bias voltage on the protonconductive paths of an SPE-bl-1 membrane were studied using a CS-AFM. $^{40}$ At a higher voltage and current density, CS-AFM images clearly showed the increase of proton conductive areas on SPE-bl-1. We mentioned both reversible and irreversible changes of the conductive paths, and the irreversible process was related to the conditioning of the membrane electrode assembly (MEA). ${ }^{40}$ In this study, AFM measurements on SPK-bl-1 were also carried out at different bias voltages at $50^{\circ} \mathrm{C}$ and $40 \% \mathrm{RH}$. Topography and current images in the same position of $1 \mu \mathrm{m} \times 1 \mu \mathrm{m}$ were obtained simultaneously at different bias voltages from $-0.4,-0.6$, up to $-0.8 \mathrm{~V}$ subsequently. Figures $8(\mathrm{a} 1), 8(\mathrm{~b} 1)$ and $8(\mathrm{c} 1)$ show the morphological images obtained at $-0.4,-0.6$ and $-0.8 \mathrm{~V}$, respectively. The images are very similar, thus, little influence of the bias voltage existed on the surface morphology. ${ }^{40}$ Figures $8(\mathrm{a} 2), 8(\mathrm{~b} 2)$, and $8(\mathrm{c} 2)$ show current images at $-0.4,-0.6$ and $-0.8 \mathrm{~V}$, respectively. Although the surface morphology was very similar regardless of the bias voltage, the current images changed significantly. The closelook at the current images in Figs. 8(a2) and 8(b2) reveals that with increasing the applied bias voltage from -0.4 to $-0.6 \mathrm{~V}$, the conductive areas observed at a lower voltage remained at the same locations and became larger and brighter, whereas new conductive areas also appeared. Interestingly, however, by the voltage increase from $-0.6 \mathrm{~V}$ [Fig. 8(b2)] to $-0.8 \mathrm{~V}$ [Fig. 8(c2)], the number of proton conductive spots was almost constant in spite of the increase in current. This is very different from the results on SPE-bl-1, on which the proton conductive spots continuously increased from -0.4 to $-0.8 \mathrm{~V}^{40}$

Figure 9 shows the size distribution histograms of the proton conductive spots on the SPK-bl-1 surface at different tip bias voltages at $50^{\circ} \mathrm{C}$ and $40 \% \mathrm{RH}$. The diameter of the proton-conductive spots and the size distribution increased and broadened, from $10 \pm 4$
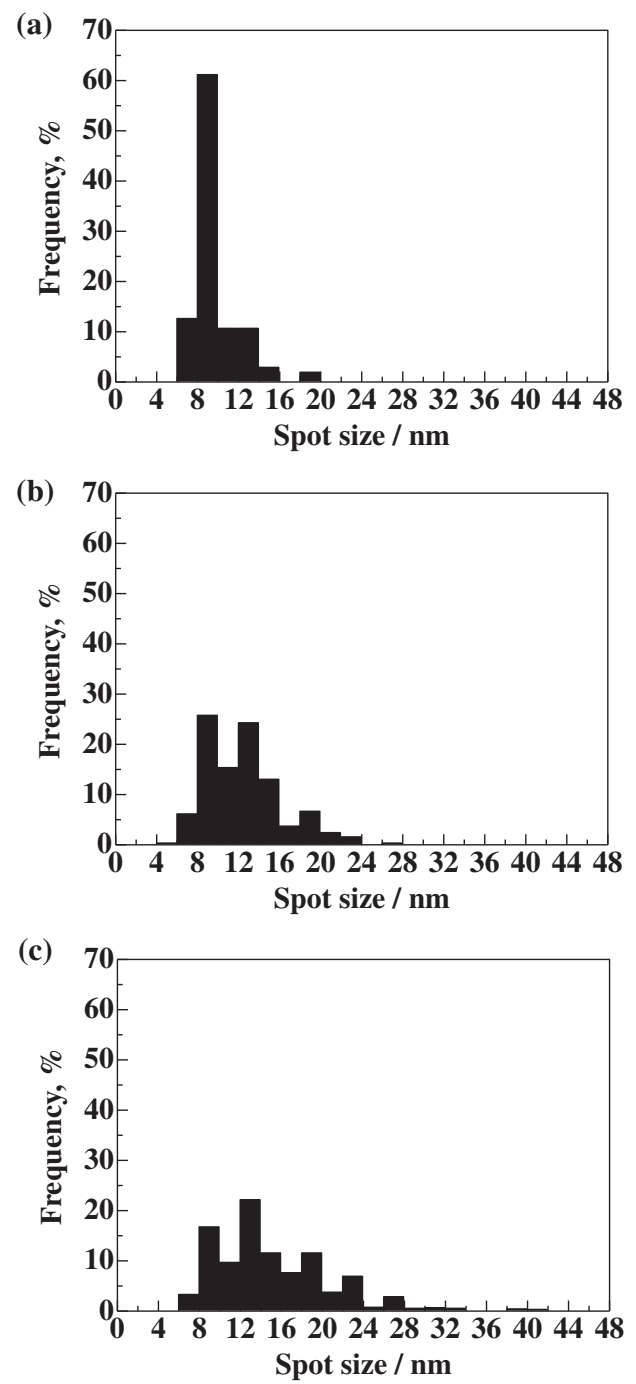

Figure 9. Size distributions of the proton conducting spots obtained at -0.4 (a), -0.6 (b) and $-0.8 \mathrm{~V}$ (c) at $50^{\circ} \mathrm{C}$ and $40 \% \mathrm{RH}$.

$\mathrm{nm}$ at $-0.4 \mathrm{~V}, 13 \pm 7 \mathrm{~nm}$ at $-0.6 \mathrm{~V}$, to $15 \pm 9 \mathrm{~nm}$ at $-0.8 \mathrm{~V}$, with increasing the bias voltage [Fig. 10(a)]. In each histogram, peak is almost unimodal, contrary to the results shown in Fig. 5. Therefore, this increase in spot size is thought to be mainly due to the increase in diameter itself and partially due to merging of spots. In the case of SPE-bl-1, humidity gave little influence on the size of the conducting spots, ${ }^{36}$ but high voltage enlarged the spot size. ${ }^{40}$ On SPK-bl-1, both humidity and high voltage made the spot size larger. The numbers of proton-conductive spots are shown in Fig. 10(b). At $-0.4,-0.6$ and $-0.8 \mathrm{~V}$, the spot number was 103,943 , and 907 , respectively. Therefore, the number increased from -0.4 to $-0.6 \mathrm{~V}$ but kept constant at $-0.8 \mathrm{~V}$, probably because of the complete development of proton conductive paths at $-0.6 \mathrm{~V}$. The ratio of the proton-conductive area as a function of the applied bias voltage is shown in Fig. 10(c), in which the surface conductive area was calculated from the sum of the multiplication of the number and the area of the proton-conductive spots. The ratio of proton conductive regions on the membrane surface was 1,13 and $19 \%$ at $-0.4,-0.6$ and $-0.8 \mathrm{~V}$, respectively. The STEM images have shown that the ratio of the hydrophilic domains was approximately $25 \%$, thus those values seem reasonable. Surprisingly, the ratio of the proton conductive regions on SPE-bl- 1 became $55 \%$ at the bias voltage of $-0.8 \mathrm{~V},{ }^{40}$ larger than the ratio of the hydrophilic domains $(30 \%) .{ }^{36}$ This large difference between the hydrophilic domain $(30 \%)$ and the surface conductive area $(55 \%)$ at a high current flow 
(a)

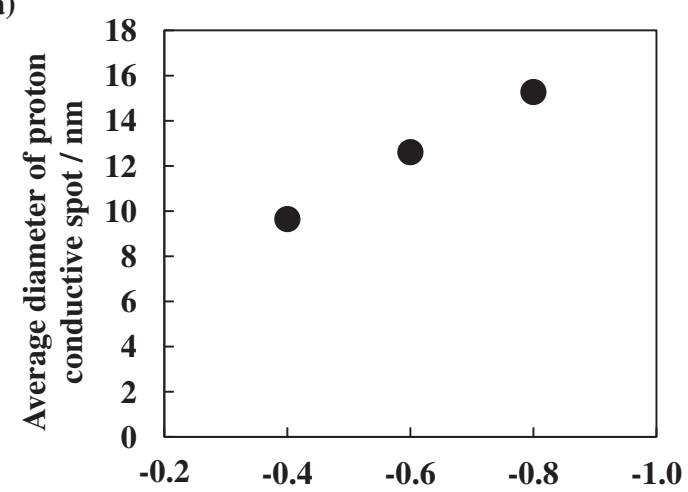

(b)

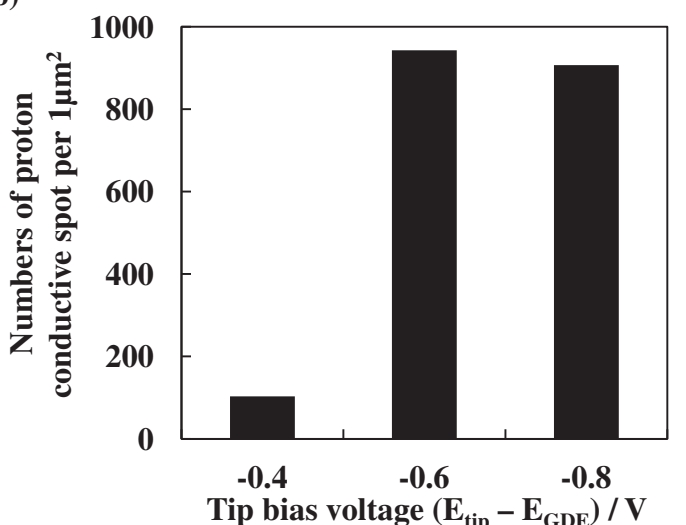

(c)

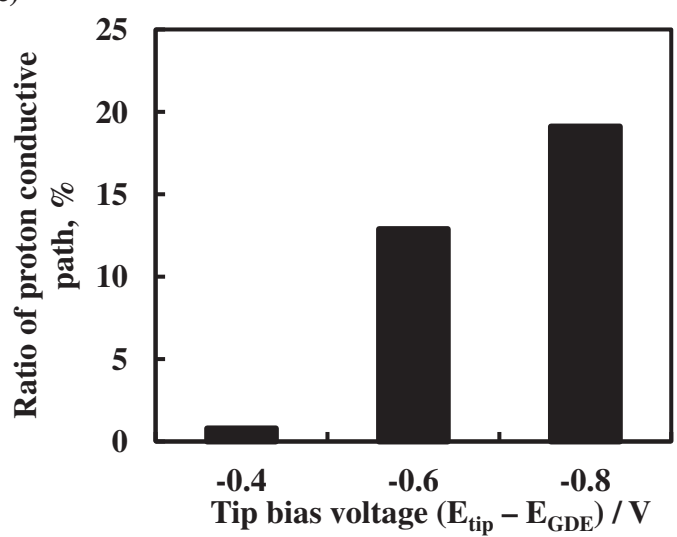

Figure 10. Average diameters (a), numbers of proton conducting spots in $1 \mu \mathrm{m}^{2}$ (b), and ratios of proton conducting areas (c) at -0.4 , -0.6 , and $-0.8 \mathrm{~V}$ at $50^{\circ} \mathrm{C}$ and $40 \% \mathrm{RH}$.

on SPE-bl-1 with its lower IEC and water uptake is not clear at the moment, but at a high voltage, the small hydrophilic domains embedded in hydrophobic domains might be activated and observed by CS-AFM, which could play roles during the power generation. On the other hand, the SPK-bl-1 membrane showed less influence of high voltage/current showing smaller change in current distribution than on SPE-bl-1 possibly because of the highly-established phase separation.

Membrane surfaces have been reported to be mobile. Grazing incident SAXS was used to find rearrangement of the Nafion surface in vapor and under water, which eventually changed the contact angles of water droplets. ${ }^{41}$ Recently, the lamellar surface structures and conductivities of Nafion and Aquivion ${ }^{\odot}$ have been also examined by $\mathrm{AFM},{ }^{37}$ where current flows were required to activate membranes as shown in this study. The mobility and transformability of membrane surfaces and the membrane-catalyst layer interfaces during the power generation are the issues to be understood for the further improvement of the MEAs.

\section{Conclusions}

CS-AFM measurements were carried out on an SPK-bl-1 membrane under the controlled $\mathrm{H}_{2}$ atmosphere at different temperatures, humidities, and bias voltages. The proton conductive spots were clearly imaged on the surface, which were distributed rather inhomogeneously especially at lower temperature and humidity but became more homogeneous at higher temperature, humidity, and bias voltage with increased conductive spots. The high proton conductivity of SPK-bl-1 membrane at high humidity and temperature could be explained by the increase in the number of the active paths possibly due to the sufficient connectivity between neighboring hydrophilic clusters. A higher water uptake of the membrane could partially attribute to this better connectivity.

\section{Acknowledgments}

This work was supported by the "Research on Nanotechnology for High Performance Fuel Cells (HiPer-FC)" project from the New Energy and Industrial Technology Development Organization (NEDO) of Japan.

\section{References}

1. L. Carrette, K. A. Friedrich, and U. Stimming, Fuel Cells, 1, 5 (2001).

2. M. A. Hickner and B. S. Pivovar, Fuel Cells, 5, 213 (2005).

3. T. Kobayashi, M. Rikukawa, K. Sanui, and N. Ogata, Solid State Ionics, 106, 219 (1998).

4. K. D. Kreuer, J. Membr. Sci., 185, 29 (2001).

5. K. Miyatake, Y. Chikashige, and M. Watanabe, Macromolecules, 36, 9691 (2003).

6. M. A. Hickner, H. Ghassemi, Y.-S. Kim, B. R. Einsla, and J. E. McGrath, Chem. Rev. 104, 4587 (2004).

7. B. R. Einsla, Y.-T. Hong, Y. S. Kim, F. Wang, N. Gunduz, and J. E. McGrath, J. Polym. Sci., Part A: Polym. Chem., 42, 862 (2004).

8. B. Smitha, S. Sridhar, and A. A. Khan, J. Membr. Sci., 259, 10 (2005).

9. S. H. Tian, D. Shu, S. J. Wang, M. Xiao, and Y. Z. Meng, Fuel Cells, 7, 232 (2007).

10. M. Schuster, K. D. Kreuer, H. T. Andersen, and J. Maier, Macromolecules, 40, 598 (2007).

11. H. Hou, M. L. D. Vona, and P. Knauth, J. Membr. Sci., 423-424, 113 (2012).

12. K. Miyatake, Y. Chikashige, E. Higuchi, and M. Watanabe, J. Am. Chem. Soc., 129, 3879 (2007).

13. B. Bae, K. Miyatake, and M. Watanabe, J. Membr. Sci., 310, 110 (2008).

14. B. Bae, K. Miyatake, and M. Watanabe, ACS Appl. Mater. Interfaces, 1, 1279 (2009).

15. B. Bae, K. Miyatake, and M. Watanabe, Macromolecules, 43, 2684 (2010).

16. B. Bae, T. Yoda, K. Miyatake, H. Uchida, and M. Watanabe, Angew. Chem., Int. Ed., 49, 317 (2010).

17. B. Bae, T. Yoda, K. Miyatake, M. Uchida, H. Uchida, and M. Watanabe, J. Phys. Chem. B, 114, 10481 (2010).

18. B. Bae, T. Hoshi, K. Miyatake, and M. Watanabe, Macromolecules, 44, 3884 (2011).

19. T. Miyahara, T. Hayano, S. Matsuno, M. Watanabe, and K. Miyatake, ACS Appl. Mater. Interfaces, 4, 2881 (2012).

20. K. Schmidt-Rohr and Q. Chen, Nat. Mater, 7, 75 (2008).

21. D. A. Bussian, J. R. O'Dea, H. Metiu, and S. K. Buratto, Nano Lett., 7, 227 (2007).

22. E. Aleksandrova, R. Hiesgen, K. A. Friedrich, and E. Roduner, ChemPhysChem, 8, 519 (2007).

23. X. Xie, O. Kwon, Z. Da-Ming, T. V. Nguyen, and G. J. Liu, J. Phys. Chem. B, 111, 6134 (2007).

24. E. Aleksandrova, R. Hiesgen, K. A. Friedrich, and E. Roduner, Phys. Chem. Chem. Phys., 9, 2735 (2007).

25. N. Takimoto, A. Ohira, Y. Takeoka, and M. Rikukawa, Chem. Lett., 37, 164 (2008).

26. Y. Kang, O. Kwon, X. Xie, and D.-M. Zhu, J. Phys. Chem. B, 113, 15040 (2009).

27. R. Hiesgen, E. Aleksandrova, G. Meichsner, I. Wehl, E. Rodunder, and K. A. Friedrich, Electrochim. Acta, 55, 423 (2009).

28. O. Kwon, S. Wu, and D.-M. Zhu, J. Phys. Chem. B, 114, 14989 (2010).

29. D. G. Sanchez, D. G. Diaz, R. Hiesgen, I. Wehl, and K. A. Friedrich, J. Electroanal. Chem., 649, 219 (2010). 
30. O. Kwon, Y. Kamg, S. Wu, and D.-M. Zhu, J. Phys. Chem. B, 114, 5365 (2010).

31. O. Kwon, Y. Kamg, S. Wu, and D.-M. Zhu, ECS Trans., 33, 1035 (2010).

32. Q. He, A. Kusoglu, I. T. Lucas, K. Clark, A. Z. Weber, and R. Kostecki, J. Phys. Chem. B, 115, 11650 (2011).

33. E. Aleksandrova, S. Hink, R. Hiesgen, and E. Rodunder, J. Phys.: Condens. Matter, 23, 234109 (2011)

34. N. Takimoto, S. Takamuku, M. Abe, A. Ohira, H.-S. Lee, and J. E. McGrath, J. Power Sources, 194, 662 (2009).

35. S. Hink, E. Aleksandrova, and E. Rodunder, ECS Trans., 33, 57 (2010).

36. M. Hara, D. Hattori, J. Inukai, B. Bae, T. Hoshi, M. Hara, K. Miyatake, and M.
Watanabe, J. Phys. Chem. B, 117, 3892 (2013).

37. R. Hiesgen, S. Helmly, T. Morawietz, X.-Z. Yuan, H. Wang, and K. A. Friedrich, Electrochim. Acta, 110, 292 (2013).

38. J. M. Song, H. Uchida, and M. Watanabe, Electrochemistry, 73, 189 (2005).

39. M. Aoki, N. Asano, K. Miyatake, H. Uchida, and M. Watanabe, J. Electrochem. Soc., 153, A1154 (2006).

40. M. Hara, D. Hattori, J. Inukai, M. Hara, K. Miyatake, and M. Watanabe, J. Electroanal. Chem., 716, 158 (2014).

41. M. Bass, A. Berman, A. Singh, O. Konovalov, and V. Greger, Macromolecules, 44, 2893 (2011) 